\title{
Parametric Variation Based Analysis AND Effective Design of Rectangular Patch Antenna for Bluetooth Application
}

\author{
Riaz Ahmed Soomro ${ }^{1}$, Ahsan Memon ${ }^{2}$, Anum Talpur ${ }^{3}$, Daniyal Akhtar ${ }^{4}$, \\ Pinkesh Rajani ${ }^{5}$, Natasha Baloch ${ }^{6}$ \\ 1,2,3,4,5,6 Institute of Communication Technologies (ICT), Department of Telecommunication Engineering, \\ Mehran U.E.T, Jamshoro, Pakistan
}

\begin{abstract}
This paperdevelops an understanding of creating and improving the design of microstripantenna by the performance analysis of resultsfromitsvarious configurationsrelating to rectangular patch microstripantenna. Furthermore, itaccommodates a simulated patch antennawith effective results for bluetooth applicationsatafrequency of $2.4 \mathrm{GHz}$. The proposed antenna is not only designed on the formulated calculations but also analyzed on different sizes, positions and orientations of substrate, feeding point and slots respectively.

Propagation parameters are greatly improved by amendments suggested by the analysis of the variation based studies provided by this paper. The initial resultsobtained using formulae based designs are compared with the ameliorated results to illustrate the effects of such variations on antenna parameters. The final antenna show significantly improved return losses of $-46.7 \mathrm{~dB}$, VSWR of 1.0093, Bandwidth of $180 \mathrm{MHz}$ and a far field radiation pattern with a gain of $2.2782 \mathrm{~dB}$. The Antenna designed is optimized and interpreted with Ansoft HFSS 13.0 simulator.
\end{abstract}

Keywords: Bluetooth, rectangular patch antenna, feedpoint, trial and error method, slot orientation, wide bandwidth.

\section{Introduction}

The evolution of patch antenna in the past few years, has greatly optimized the performance of communication systems. In particular, size and efficiency of antennae have been greatly improved due to research in patch antennae.[1]shows a detailed study of patch antennae comprising of characteristics that improve bandwidth.Microstrip patch antennaspecialty over other antennaeare low profile, compactness, light weight and ease of fabrication. Applications, in particular, Wireless LAN, Bluetooth, Zigbee, Missile guiding systems and Microwave engineering require systems with small sizes, which is comparatively easier toachieve through the use of patch antennae. The ISM band inhibitsone of the largestconcentration of applications, most of which lie at the frequency of $2.4 \mathrm{GHz}$.

In wireless communications, Bluetooth Technology is a non-line-of-sight communication system that supports short distances and low data rate with an operating frequency of $2.4 \mathrm{GHz}$.

Notableresearch has been carried out and published in patch antenna designingusing T-shaped slots in ground plane [7] that provide wide bandwidth, circular patches [2] that provide dual band applications, U-notch [3] and rectangular patch[4] with improved bandwidth. In [7] a novel idea of incorporating ground plane into plane of patch was published, yielding return losses of $-35 \mathrm{~dB}$ at $2.4 \mathrm{GHz}$, whereas, in [4], a simple rectangular patch is introduced with return losses of $-30 \mathrm{~dB}$ at $2.4 \mathrm{GHz}$.

More recently, developments in patch antenna provide us with the evidence that slots in patches improve gain, bandwidth and losses exhibited by antennae, [5] show an example of high gain slot coupled patch antenna and [6] relates the creation of slot with high bandwidth application. Interestingly, different antennae configurations having change in position and orientation of slot in the patch have shown to be very different from each other.

This paper presents a study of configurations of antenna relating to feeding point, height, size of substrate and position of slot into the patch. With variations in these parameters we observe different patterns whichprovide a study of behavior of radiation parameters of an antenna. With a frequency sweep of $1 \mathrm{GHz}$ to $10 \mathrm{GHz}$, we observe changes with respect to height, length, width of substrate and position of rectangular slot and hence, we design an efficient patch antenna with a simple rectangular patch.

\section{Antenna Design Relations}

Initially, parametric equations were used to design an antenna with center frequency of $2.4 \mathrm{GHz}$. Fr4 epoxy was used as a substrate material due to its ease in application in PCB designing. It has a permittivity constant of 4.4 and a loss tangent of 0.01 .

A very effective approximation of width of patch[9] was found by: 


$$
W=\frac{c}{2 f_{o} \sqrt{\frac{\varepsilon_{r}+1}{2}}}
$$

A finite ground plane with the same size of width $\mathrm{W}$ and length $\mathrm{L}$ as of substrate is situated below the substrate. Patch, ground length and width are calculated by using transmission line model. The relative dielectric constant $\left(\varepsilon_{\mathrm{r}}\right)[9]$ of the substrate is given as

$$
\varepsilon_{r e f f}=\frac{\varepsilon_{r}+1}{2}+\frac{\varepsilon_{r}-1}{2}\left[1+12 \frac{h}{W}\right]^{-\frac{1}{2}}
$$

An effective approximation for normalized extension of length[9],[10] is given as:

$$
\Delta L=0.142 h \frac{\left(\varepsilon_{r}+0.3\right)\left(\frac{W}{h}+0.264\right)}{\left(\varepsilon_{r}-0.258\right)\left(\frac{W}{h}+0.8\right)}
$$

The effective length[9] of this patch is given by:

$$
L=L_{e f f}-2 \Delta L
$$

Effective and practical consideration feed locations[9], were found by

$$
y_{f}=\frac{W}{2} \text { and } x_{f}=\frac{L}{2 \sqrt{\varepsilon_{\text {reff }, L}}}
$$

Hence, the formula based calculations of this antenna were as, length of substrate and ground plane were $44 \mathrm{~mm}$, width of substrate and ground were 53.2763 , length of patch was approximately $28 \mathrm{~mm}$, width of patch was found to be $38 \mathrm{~mm}$, feed locations found by (5) were(19.0181,7.2943)height of substrate chosen for the simulation was chosen to be $2.54 \mathrm{~mm}$ due to its practical form available in PCB.

\subsection{Formulae Based Model Simulation}

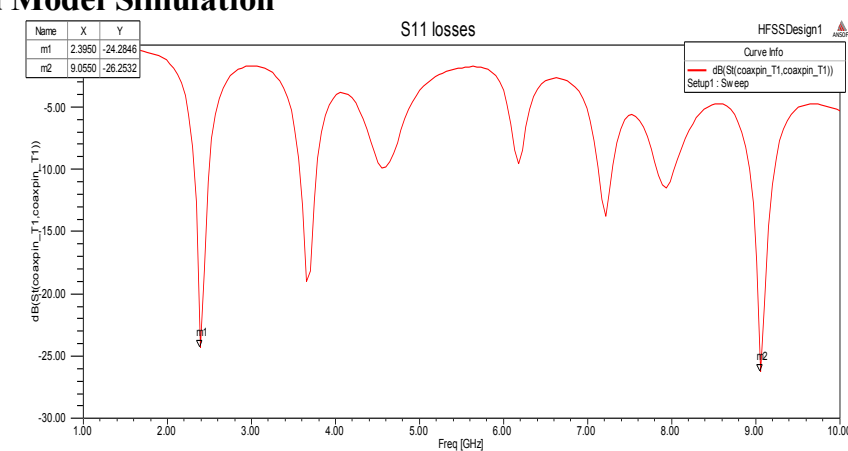

Figure 1. S11 losses of the formulated antenna

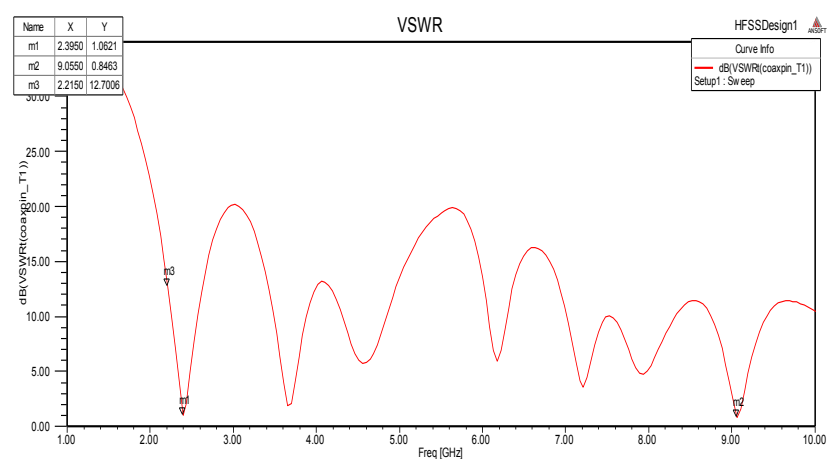

Figure 2. VSWR of the formulated antenna

The formulae based model yeilded results with S11 return losses of $-24.28 \mathrm{~dB}$ and VSWR of 1.0621 was observed at a frequency of $2.3950 \mathrm{GHz}$.

\subsection{Proposed feed location}

\section{Performance Analysis}

Feeding method we used was through coax cable with impedance of $50 \mathrm{ohm}$ due to ease of fabrication, matching and a quality of low spurious radiation. In Coax feeding method the inner conductor of the coaxial is 
attached to the radiating patch of the antenna while the outer conductor is connected to the ground plane where, the best impedance match would yield the best results.

However, direct calculation didnot provide efficient matching.Using co-ordinates of (5) for feed location, the observed return losses were- $11.8284 \mathrm{~dB}$, which conclude that design require changes for better impedance matching. By applying trial and error method used to adjust the feed point to $50 \Omega$, variations in return losses were obtained as accumulated Table 01 :

Table 1.Feed Location Based Results

\begin{tabular}{|c|c|}
\hline Feed locations $\left(X_{f}, Y_{f}\right)(\mathrm{mm})$ & Return losses ( dB ) \\
\hline$(9.3,19)$ & -5.3688 \\
\hline$(8.3 .19)$ & -7.7937 \\
\hline$(7.3,19)$ & -10.7472 \\
\hline$(6.3,19)$ & -14.5601 \\
\hline$(5.3,19)$ & -19.0056 \\
\hline$(4.3,19)$ & -24.2846 \\
\hline$(3.3,19)$ & -21.3562 \\
\hline$(2.3,19)$ & -18.0722 \\
\hline
\end{tabular}

The best match was achieved over the co-ordinates of $(4.3,19)$, resulting in return losses of $-28.4259 \mathrm{~dB}$.

\subsection{Substrate and Ground Size Impact on Design}

The proposed structure was further tested with different substrate sizes on feed points of $(4.3,19)$ and was observed to be improving after a certain point. It was observed that equalsize of ground plane and the substrate provided the best results. Hence, the size of substrate and ground was kept same at all times.

Dimensions in Table 02 were taken into account to analyze the antenna parameters.

Table 2.Substrate Location Based Results

\begin{tabular}{|c|c|c|}
\hline Length* width $(\mathbf{m m})$ & S11 Losses (dB) & VSWR (dB) \\
\hline 44,53 & -24.2846 & 1.1301 \\
\hline 45,55 & -23.0772 & 1.1509 \\
\hline 50,60 & -29.5581 & 1.0688 \\
\hline 55,65 & -22.7030 & 1.1581 \\
\hline 60,75 & -26.7099 & 1.0968 \\
\hline 65,80 & -27.0437 & 1.0930 \\
\hline 70,90 & -29.7871 & 1.0670 \\
\hline 75,95 & -28.4281 & 1.0788 \\
\hline 80,105 & -29.6398 & 1.0682 \\
\hline 95,115 & -32.0942 & 1.0510 \\
\hline 105,125 & -35.8228 & 1.0329 \\
\hline
\end{tabular}

Hence, size of substrate was chosen to be $(105,125) \mathrm{mmfor}$ further analysis, as it had the widest bandwidth and improved responses.

\subsection{Height adjustment}

Selected substrate size (i.e. $105 \mathrm{~mm} * 125 \mathrm{~mm}$ ) was then examined under height variations. 10 equidistant points were analyzed based on the permitted range of .003lambda $<\mathrm{h}<.05$ lambda. The observed results are displayed in Table 3.

Table 3.Height Adjustments in Substrate

\begin{tabular}{|c|c|c|c|}
\hline Height & $\begin{array}{c}\text { Resonant } \\
\text { Frequency }\end{array}$ & S11 & VSWR \\
\hline 0.375 & 4.5 & -13.17 & 1.5745 \\
\hline 1.0278 & 3.745 & -16.38 & 1.2849 \\
\hline 1.6806 & 2.44 & -28.70 & 1.0407 \\
\hline 2.3334 & 2.395 & -25.46 & 1.0487 \\
\hline 2.9862 & 2.395 & -21.79 & 1.172 \\
\hline 3.639 & 2.350 & -33.35 & 1.0407 \\
\hline
\end{tabular}




\begin{tabular}{|c|c|c|c|}
\hline 4.2918 & 2.3050 & -27.47 & 1.1014 \\
\hline 4.9446 & 2.3050 & -25.77 & 1.1064 \\
\hline 5.5974 & 4.66 & -22.71 & 1.1268 \\
\hline 6.25 & 4.555 & -22.39 & 1.1336 \\
\hline
\end{tabular}

Referring to Table 3, it could be seen that improvements in VSWR were observed as height was enlarged, whereas, losses were trim downat mediocre values of permitted height.

Observation suggested a height selection between 2.3334 and 4.2918; hence, we selected the size to be 2.54 and proceeded with its further amendments.

\subsection{Slot Orientation}

\subsubsection{Horizontal}

Horizontal slots wasproduced with a length*width of $21 * 1 \mathrm{~mm}^{2}$. The slot wastraversed from at least 1 point from one edge of the patch to at most 3 points from other edge as:

Table 4. Horizontal Slot Orientation

\begin{tabular}{|c|c|c|c|c|}
\hline $\begin{array}{c}\text { Points from } \\
\text { edge (mm) }\end{array}$ & $\begin{array}{c}\text { Resonant } \\
\text { frequency } \\
(\mathbf{G H z})\end{array}$ & $\begin{array}{c}\text { Return } \\
\text { losses } \\
(\mathbf{d B})\end{array}$ & Gain (dB) & VSWR \\
\hline 1 & 2.215 & -25.3841 & 1.1829 & 1.1137 \\
\hline 4 & 1.99 & -24.1012 & -3.6133 & 1.1330 \\
\hline 8 & 3.5650 & -22.3378 & -4.4762 & 1.1654 \\
\hline 13 & 4.78 & -25.1358 & -2.3483 & 1.1172 \\
\hline 18 & 8.425 & -14.3974 & 0.0779 & 1.4710 \\
\hline 21 & 8.65 & -23.9915 & 1.2457 & 1.1348 \\
\hline
\end{tabular}

Simulated results showed a gradual increase in resonant frequency from $2.15 \mathrm{GHz}$ to $8.65 \mathrm{GHz}$ as it moves towards the feed.

\subsubsection{Vertical}

Furthermore, the design was evaluated on the basis of vertical slot orientations. Samples of slot sizes were taken. Best results were inhibited in the slot width of $1 \mathrm{~mm}$ and a height of $21 \mathrm{~mm}$. Various orientations were experimented on the slot. The slot was moved from beside the feed to the end of patch, yielding results as illustrated in Table 5 .

Table 5.Vertical Slot Orientation

\begin{tabular}{|c|c|c|c|}
\hline $\begin{array}{c}\text { Points away } \\
\text { from edge }\end{array}$ & $\begin{array}{c}\text { Return } \\
\text { Losses(dB) }\end{array}$ & $\begin{array}{c}\text { Gain } \\
\text { (dB) }\end{array}$ & VSWR \\
\hline 1 & -33.1402 & 2.3975 & 1.045 \\
\hline 4 & -30.6349 & 2.3306 & 1.0606 \\
\hline 8 & -31.9108 & 2.3984 & 1.0521 \\
\hline 13 & -46.7054 & 2.2782 & 1.0093 \\
\hline 19 & -31.9629 & 2.4104 & 1.0518 \\
\hline 25 & -35.0115 & 2.3461 & 1.0362 \\
\hline 30 & -35.8225 & 2.3138 & 1.0329 \\
\hline 34 & -33.0617 & 2.3554 & 1.0455 \\
\hline 37 & -33.5953 & 2.3774 & 1.0427 \\
\hline
\end{tabular}

Considerable decrement in Return Losses was observed as the slot was traversed towards the feeding point, whereas, minor changes were observed in VSWR and Gain. The slot creation at $13 \mathrm{~mm}$ from the corner gave us further optimized results in terms of Gain, VSWR, Bandwidth and return losses at $2.395 \mathrm{GHz}$.

\section{Final Design}

Taking into account all the optimized results, we constructed an antenna with dimensions that provided best results after all amendments.Following were the simulated results 


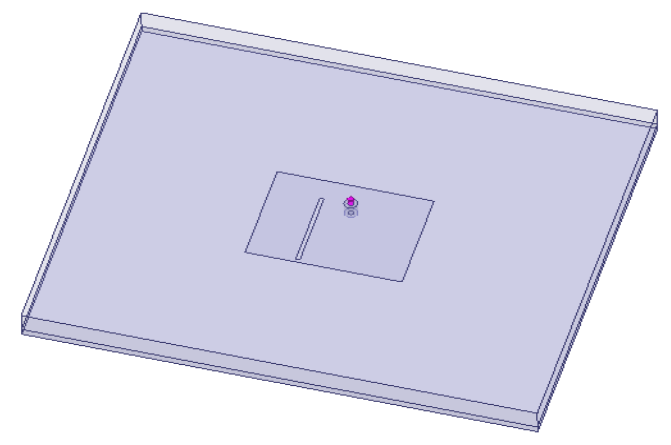

Figure 3. HFSS model of final antenna

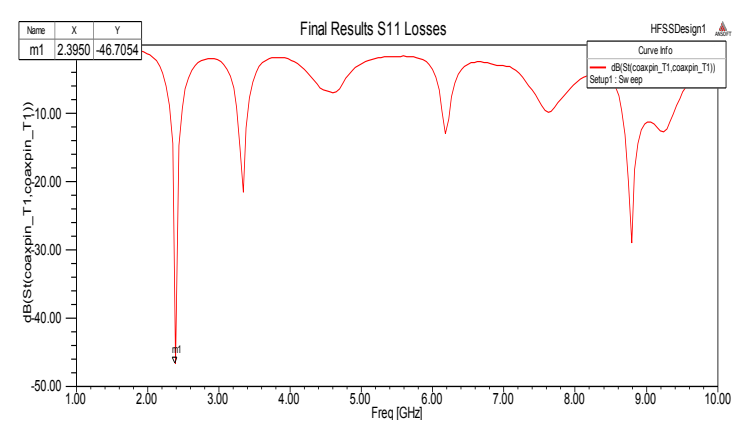

Figure 4. Return losses of final antenna

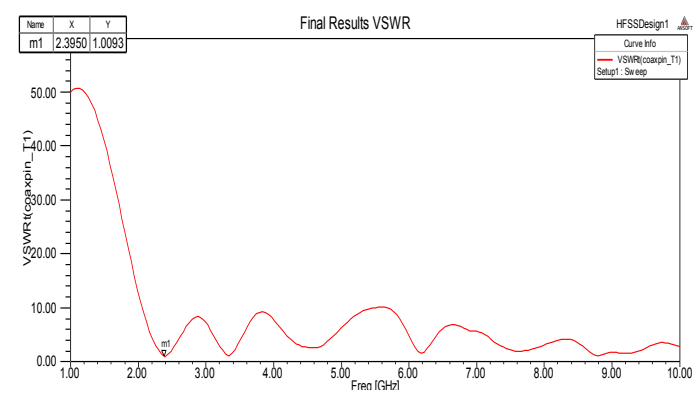

Figure 5. VSWR of final antenna

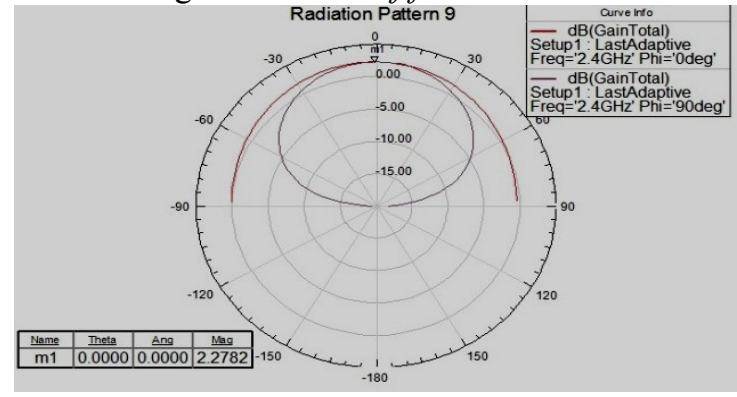

Figure 6. Radiation pattern of final antenna

Table 6. Design Parameters

\begin{tabular}{|c|c|}
\hline Material & Fr4 Epoxy \\
\hline Electric Permitivity & 4.4 \\
\hline Loss Tangent & .02 \\
\hline Patch Length & $28 \mathrm{~mm}$ \\
\hline Patch Width & $38 \mathrm{~mm}$ \\
\hline Substrate Length & $105 \mathrm{~mm}$ \\
\hline Substrate Width & $125 \mathrm{~mm}$ \\
\hline Ground Length & $105 \mathrm{~mm}$ \\
\hline Ground Width & $125 \mathrm{~mm}$ \\
\hline Substrate Height & $2.54 \mathrm{~mm}$ \\
\hline
\end{tabular}


Table 7. Results

\begin{tabular}{|c|c|}
\hline Frequency & $2.3950 \mathrm{GHz}$ \\
\hline Bandwidth & $180 \mathrm{MHz}$ \\
\hline VSWR & $1.0093 \mathrm{~dB}$ \\
\hline Return losses & $-46.7054 \mathrm{~dB}$ \\
\hline Gain & $2.2782 \mathrm{~dB}$ \\
\hline
\end{tabular}

\section{Conclusion}

Multiple design patterns of patch antennae were analyzed and one completely designed patch antenna was constructed in this research. The patterns showed that up to two times increases in substrate size from the formulated values will provide better return losses. Ground and substrate provide better results when of identical size.Height of substrate effects resonant frequency of antenna. Horizontal slot, when taken near the feeding point, impinge on frequencies from $1 \mathrm{GHz}$ to $5 \mathrm{GHz}$ and when taken away from feed point, affects $5 \mathrm{GHz}$ to $10 \mathrm{GHz}$. Vertical slot, when taken midway, from feed to end, provided the best results.

Hence, an antenna with a gain of $2.2782 \mathrm{~dB}$, VSWR of 1.0093 , bandwidth of $180 \mathrm{MHz}$ and return losses of $-46.7 \mathrm{~dB}$ at $2.3950 \mathrm{GHz}$ was designed.

\section{Acknowledgements}

The authors would like to thank their supervisors, Prof. Dr. Bhawani Shankar Chowdhry andProf. Dr. Aftab Ahmed Memonforproviding their valuable guidance and technical assistance during research.

\section{References}

[1] Kai-Fong Lee, Fellow IEEE, and Kin-Fai Tong, Member IEEE, "Patch Antennas Basic Characteristics and Some Recent Advances", Vol. 100, No. 7, July 2012 Proceedings of the IEEE.

[2] M. M. Abd-Elrazzak, Member, IEEE, and Ibrahim S. AI-Nomay“A Design of a Circular Microstrip Patch Antenna for Bluetooth and HIPERLAN Applications”, The 9th Asia-Pacific conference on Communications, Malaysia, APCC 2003.

[3] Linxi Zhang, Qi Zhang, Chufeng $\mathrm{Hu}$ "The Influence of Dielectric Constant on Bandwidth ofU-notch Microstrip Patch Antenna",Proceedings of 2010 IEEE International Conference on Ultra-Wideband (ICUWB2010),978-1-4244-5306-1/10C2010 IEEE.

[4] T.S.P. See and ZhiNing Chen, "Design of Broadband Dual-Polarization Stacked Antennas for Bluetooth Applications".ICCS 2002.

[5] OmidHoseiniIzadi, MandanaMehrparvar, "A Compact Slot Antenna With Novel E- shaped Coupling Aperture", 5thInternational Symposium on Telecommunications (IST'2010).

[6] Mark S. Reese, Constantine A. Balanis, and Craig R. Birtcher, “Design of a Stacked Patch Antenna Using HFSS”.

[7] W. Swelam, "Triple-Band T-Shape Patch Antenna with Slotted Ground Plane for PCS, UMTS and Bluetooth Communication Systems".

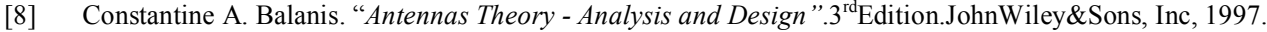

[9] Shu Yan and Qing Zhang, "A Novel Dual- Frequency and Dual-polarized Antenna array for wireless sensor networks GPRS module of Cluster Nodes", ICCSP-'12. 